\title{
CORRIGENDUM
}

\section{Role of brain transmigrating neutrophils in depression-like behavior during systemic infection}

A Aguilar-Valles, J Kim, S Jung, B Woodside and GN Luheshi

Molecular Psychiatry (2015) 20, 413-414; doi:10.1038/mp.2014.173; published online 3 February 2015

Correction to: Molecular Psychiatry (2014) 19, 599-606; doi:10.

1038/mp.2013.137

In Figure 1f, the representative dot plots were incorrectly placed

and identified. The corrected Figure 1 is shown below.

a

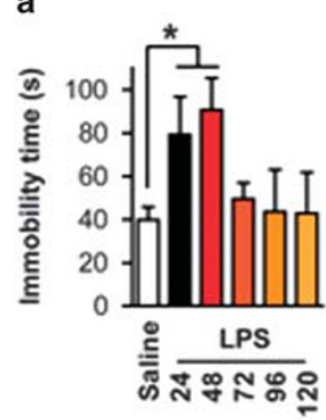

e

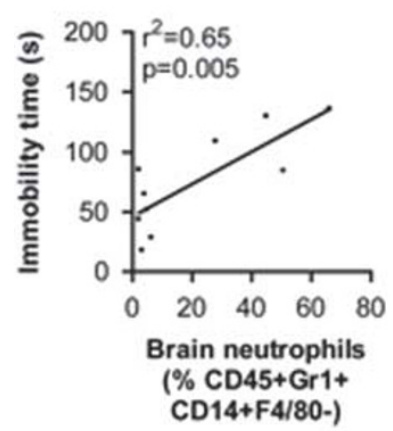

b

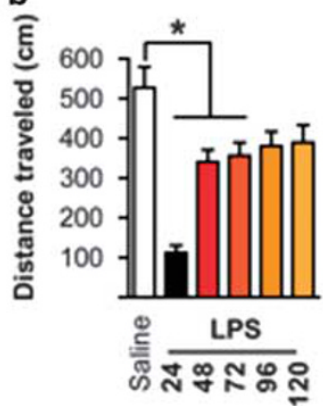

f

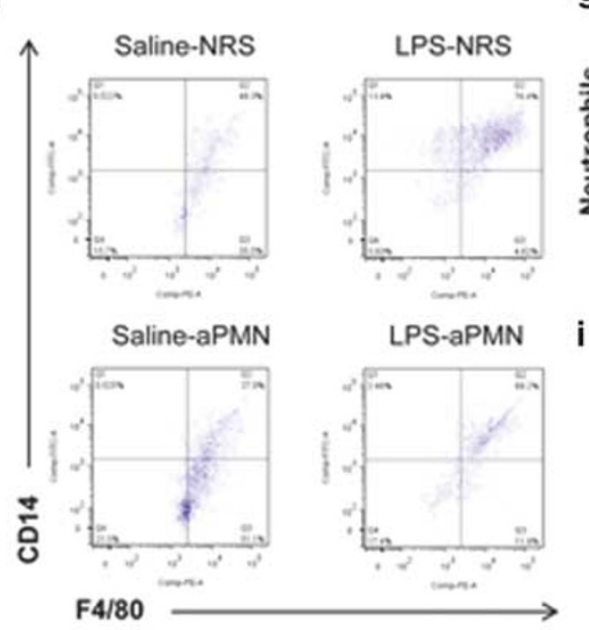

C

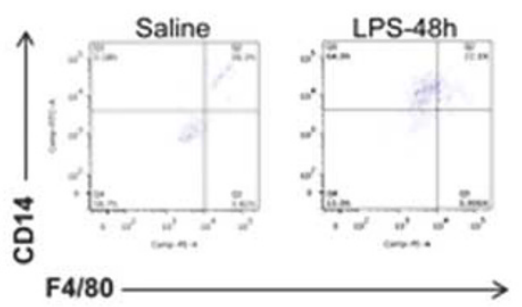

g
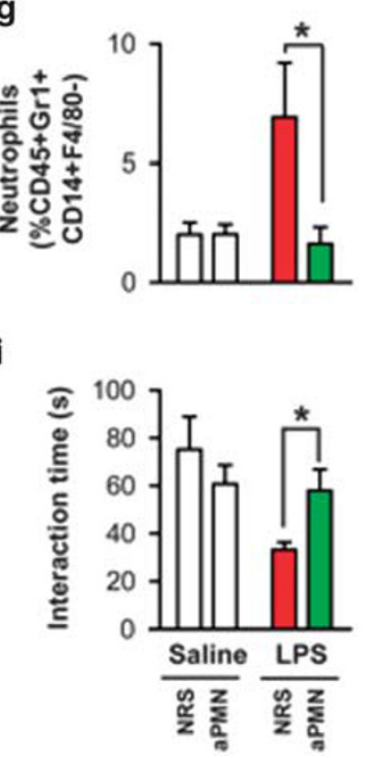

h

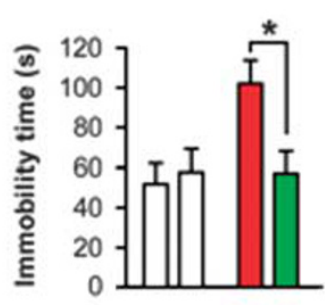

j

d
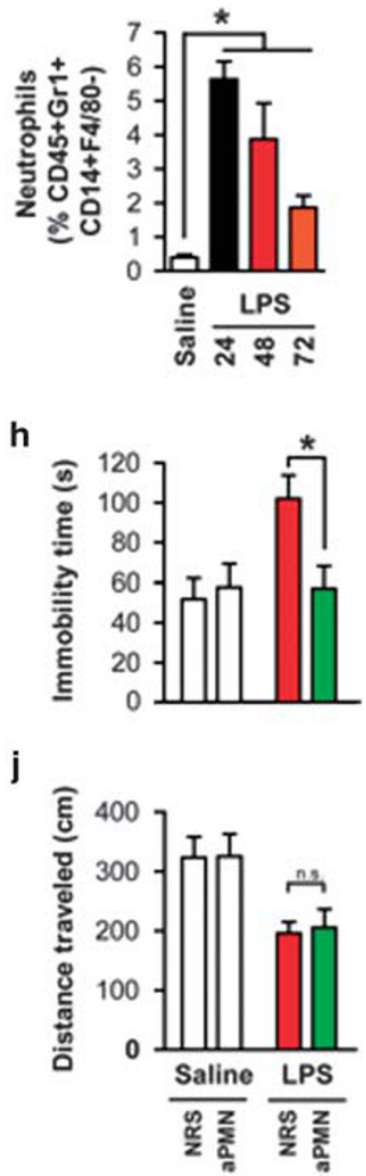

Additionally, some of the information in the Materials and Methods section, in the second paragraph under 'Treatment and Experimental Procedures,' was incorrect. The anti-polymorphonuclear (aPMN) treatment $\left(2 \mathrm{mg} \mathrm{kg}^{-1}\right.$ injected at 0 and $24 \mathrm{~h}$ after saline or lipopolysaccharide (LPS) treatment) did not induce neutropenia, as the circulating neutrophil levels were not reduced below control (saline-normal rabbit serum) following the treatment
(Supplementary Figure 4A). However, aPMN was effective in reducing the levels of LPS-induced neutrophils in the circulation (Supplementary Figure 4a) and in the brain (Figure if and g). As support, the authors have provided below a representative plot of circulating neutrophils determined by fluorescence-activated cell sorting (FACS), as performed for the brain samples in Figures if and $\mathrm{g}$ (\% of CD45+Gr1+CD14+F4/80 cells). 


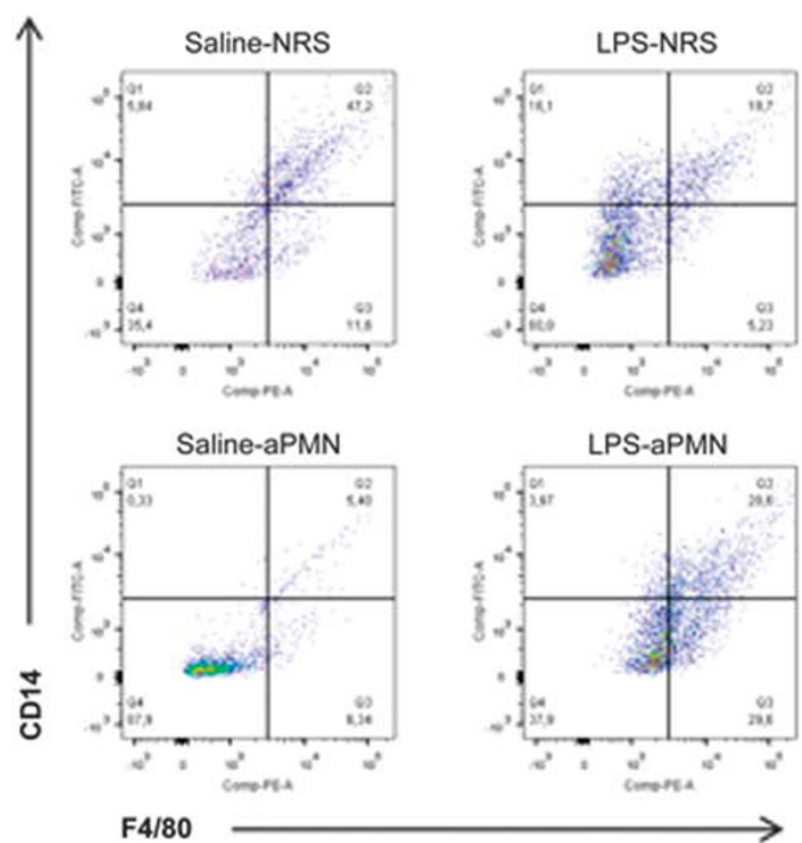

Representative FACS plots of blood neutrophils induced by LPS and reduced by anti-polymorphonuclear antibody. Mice were treated with saline or LPS as described in the text. Normal rabbit serum or aPMN antiserum was administered 0 and $24 \mathrm{~h}$ after saline or LPS injections. The mice were killed $48 \mathrm{~h}$ after saline or LPS treatment, and the blood was collected in tubes containing 1 ml of phosphate-buffered saline (PBS) with $5 \mu \mathrm{M}$ EDTA. Immediately after, samples were incubated with $10 \mathrm{ml}$ of red blood cell lysis buffer (eBioscience) for 5 min at room temperature. The lysis reaction was stopped by adding $30 \mathrm{ml}$ of PBS. After spinning $\left(400 \mathrm{~g}\right.$ for $10 \mathrm{~min}$ at $\left.4{ }^{\circ} \mathrm{C}\right)$, cells were resuspended in FACS buffer and stained as described in the text. Neutrophils were identified as in the brain (\% of CD45+Gr1+CD14+F4/80 cells). Representative dot plots for each experimental group are shown. 